Purdue University Purdue e-Pubs

$3-1-2008$

\title{
Permeability and Thermal Transport in Compressed Open-Celled Foams
}

\author{
Ravi Annapragada \\ asravi@purdue.edu \\ S V. Garimella \\ Purdue University, sureshg@purdue.edu \\ Jayathi Y. Murthy \\ School of Mechanical Engineering, Purdue University, jmurthy@purdue.edu
}

Follow this and additional works at: http://docs.lib.purdue.edu/coolingpubs

Annapragada, Ravi; Garimella, S V.; and Murthy, Jayathi Y., "Permeability and Thermal Transport in Compressed Open-Celled Foams" (2008). CTRC Research Publications. Paper 95.

http://dx.doi.org/10.1080/10407790802154173

This document has been made available through Purdue e-Pubs, a service of the Purdue University Libraries. Please contact epubs@purdue.edu for additional information. 


\title{
Permeability and Thermal Transport in Compressed Open-Celled Foams *
}

\author{
S. Ravi Annapragada, Jayathi Y. Murthy, Suresh V. Garimella ${ }^{\dagger}$, \\ School of Mechanical Engineering, 585 Purdue Mall, Purdue University, \\ West Lafayette, IN-47907 USA
}

\begin{abstract}
A computational methodology is proposed to describe the fluid transport in compressed opencelled metallic foams. Various unit-cell foam geometries are numerically deformed under uniaxial loads using a finite element method. An algorithm is developed and implemented to deform the fluid domain mesh inside the unit-cell foam based on the deformed solid unit-cell geometry. Direct simulations of the fluid transport in these deformed meshes are then performed over a range of Reynolds numbers used in practical applications. The model is validated against available experimental results and correlations. A corrected model is proposed for the permeability of compressed foams as a function of strain for flows transverse to the direction of compression. The thermal conductivity of fluid-saturated foams is also computed. Compression of foams increases the conductivity transverse to the direction of compression and decreases the conductivity parallel to it.
\end{abstract}

* Submitted for possible publication in Numerical Heat Transfer, March 2008

${ }^{\dagger}$ Corresponding author, Email: sureshg@ purdue.edu, Tel: 765-494-5646, Fax: 765-494-0539 


\section{NOMENCLATURE}

a edge length of the unit cell, $\mathrm{m}$
A area, $\mathrm{m}^{2}$
Superscripts
$\mathrm{C}_{\mathrm{P}} \quad$ specific heat, $\mathrm{J} \mathrm{g}^{-1} \mathrm{~K}^{-1}$
average or mean
D diameter of the pore, $m$
Da Darcy number
Subscripts
E Young's modulus, $\mathrm{Nm}^{-2}$
0 uncompressed
f friction factor
B bulk
$\mathrm{J}$ diffusion flux vector, $\mathrm{m}^{2} \mathrm{~s}^{-1}$
bc body center
$\mathrm{K}$ permeability, $\mathrm{m}^{2}$
comp compression
$\mathrm{k}$ thermal conductivity, $\mathrm{Wm}^{-1} \mathrm{~K}^{-1}$
D Darcian
$\mathrm{L}$ length of the periodic module, $\mathrm{m}$
Eff effective value for the foam
$\mathrm{Nu} \quad$ Nusselt number
f fluid, foam
q" heat flux, $\mathrm{Wm}^{-2}$
$\mathrm{P}$ pressure, $\mathrm{Nm}^{-2}$
in inlet
Pr Prandtl number
int intersection
Pe Peclet number
K permeability
s solid
$\mathrm{R}$ radius of the pore, $\mathrm{m}$
sa surface area
Re Reynolds number
sc spherical cap
$\mathrm{s}$ center-to-center distance, $\mathrm{m}$
solid bulk value of solid
$\mathrm{T}$ temperature, $\mathrm{K}$
top top surface
$\mathrm{t}$ time, $\mathrm{s}$
unrestrained lateral sides free to move
$\mathrm{u}, \mathrm{v}, \mathrm{w}$ velocities along $\mathrm{x}, \mathrm{y}, \mathrm{z}$ directions, $\mathrm{ms}^{-1}$
$\mathrm{V}$ volume, $\mathrm{m}^{3}$
$\mathrm{x}, \mathrm{y}, \mathrm{z} \quad$ Cartesian coordinates

Greek

$\alpha \quad$ thermal diffusivity, $\mathrm{m}^{2} \mathrm{~s}^{-1}$

$\delta \quad$ displacement, $\mathrm{m}$

$\varepsilon \quad$ strain

$\lambda \quad$ Lame's constant

$\mu \quad$ dynamic viscosity, $\mathrm{kg} \mathrm{m}^{-1} \mathrm{~s}^{-1}$

$\rho$ density, $\mathrm{kg} \mathrm{m}^{-3}$

$\Phi \quad$ porosity 


\section{INTRODUCTION}

Open-celled foams possess a number of interesting physical properties which has led to a wide range of research studies during the last two decades. These foams have been used as sound absorbents, as scaffolds in tissue engineering, in hydrogen storage, catalysis and other applications [1,2]. More recently, metal foams have been considered for electronics cooling applications [3]. In many of these applications, low-porosity foams are created by compressing high-porosity open-celled foams. The mechanical, thermal and fluid-dynamical properties of such compressed foams are of great industrial and research interest.

Gent and Rusch made the first attempt to study the effect of compression of an open-cell polyurethane foam on the resulting fluid transport [4]. The foam was represented by an array of circular tubes. Based on this assumption, the effective cell diameter associated with the compressed foam was related to the strain $(\varepsilon)$ by the relationship, $d=d_{0}(1+\varepsilon)^{1 / 2}$. A simple model based on scaling was defined to arrive at the permeability of compressed polyurethane foams as a function of $\varepsilon$. They also experimentally observed that Darcy flow (with viscosity dominating) was valid until $R e_{D} \approx 1$, beyond which inertial forces were found to dominate. An extension to the model was proposed by Hilyard and Collier [5], who used packed-bed theory to relate permeability to compression and porosity in polyurethane foams. Mills and Lyn [6] used the Hilyard and Collier model to account for the effect of air pressure during the deformation under impact of a polyurethane foam.

Recently, Dawson et al. [7] performed controlled experiments in which foams were compressed to $80 \%$ of their original linear dimension. The flow direction was always the same as the direction of compression. For polyurethane foams, the foam was observed to exhibit elastic behavior for small amounts of compression. Beyond a certain strain $(\varepsilon=7.5 \%)$, the foams buckled along bands and the densification was observed to occur along these regions. The experiments also showed that the permeability is independent of the cell size. A model was proposed to predict the effect of applied strain on permeability, with the experiments providing an empirical model constant in the densified region.

Schulenburg et al. [8] computed pore-scale velocities in an impacted foam using the latticeBoltzmann method and compared the results to measurements made via Magnetic Resonance Imaging (MRI). Three-dimensional MRI images of the velocity fields of water flow inside the foam were obtained. The regions with velocities below a particular threshold level were assumed to constitute the foam walls. These images provided the geometry used in the lattice-Boltzmann fluid simulations. The modeling technique is specific to the pore geometry obtained from the MRI images and cannot be generalized. Also, no effective parameters such as permeability were computed from the simulations. 
The compressive behavior of metal foams is different from that of polyurethane foams. Kwon et al. [9] showed that the mode of failure in metals is through plastic collapse at the joints, finally leading to complete collapse of the cell. The flow through these metal foams has received little attention until recently. Experimental results $[10,11,12]$ for permeability of compressed metal foams available through about the year 2005 were summarized in Dukhan et al. [10]. Boomsma et al. [13] measured the thermal performance of metal foams compressed to strains of $-0.5,-0.75,-0.83$ and -0.88 . Metal foams were recommended for use in compact heat exchangers since the thermal resistance was shown to be lower, and the efficiency greater, than that of existing heat exchangers. Klein et al. [14] constructed a heat exchanger using compressed foams and studied the thermal performance relative to the extent and direction of compression for Reynolds number of 100-1000. The thermal performance was observed to be independent of the direction of compression. No effective parameters such as permeability were reported.

The research to date has concentrated on the performance of foams compressed well beyond the plastic limit and into the crushed regime. In the present work, we investigate the performance of compressed foams at compressions within the plastic-collapse limit ( $\leq 10 \%$ compression). The unit cell modeling approach of Krishnan et al. [15] forms the starting point for this work. We develop a new coupled unit-cell model to understand the effect of compression on the flow and thermal characteristics of these foams. The model is validated against experiments and correlations for polyurethane foams and is extended to model the fluid and thermal transport in metal foams.

\section{GEOMETRIC MODEL}

In this work, we use the same methodology for geometry creation as discussed in [15]. The shape of the pore is assumed to be spherical and spheres of equal volume are arranged according to the following three lattice structures: (i) BCC, body-centered cubic, (ii) FCC, face-centered cubic, and (iii) A15 lattice, which is similar to the Weaire- Phelan (WP) structure $[16,17]$. The periodic foam unit-cell geometry is obtained by subtracting the spheres at the various lattice points from the unit cell cube as shown in Figure 1a. The cross-section of the foam ligaments is a set of convex triangles (Plateau borders), all of which meet at symmetric tetrahedral vertices [16]. It is noted that there is a non-uniform distribution of metal mass along the length of the ligament, with more mass accumulating at the vertices (nodes) and resulting in a thinning at the center of the ligament as experimentally observed in foam samples by many authors (e.g., [18]). Figure 1b shows sample open-cell structures formed for three different lattice arrangements. The distinguishing features of this approach are that: (i) the geometry creation is simple; (ii) it captures many of the important features of real foams; and (iii) meshing of the geometry is easier compared to the 
approach adopted in [19] where Surface Evolver software [20] was used to obtain the geometry, which was then used for CFD calculations of pressure drop.

\section{MATHEMATICAL MODEL}

\subsection{Structural model}

A structural model is created and deformed numerically using ANSYS [20]. The fluid domain is not modeled in the structural simulation. Furthermore, due to symmetry considerations, only $1 / 8^{\text {th }}$ of the unitcell is considered (Figure 2). Periodicity is imposed on the foam boundaries to mimic the mechanical behavior of a homogeneous medium. Boundary node displacements parallel to the boundary faces are coupled through the following relation:

$$
\delta_{i}-\delta_{j}=0
$$

where $\delta_{i}$ and $\delta_{j}$ are displacements parallel to the boundary face of the boundary nodes $\mathrm{i}$ and $\mathrm{j}$. The implementation of the periodic condition for mechanical compression is illustrated in Figure 2.

A Kinematic Uniform Boundary Condition (KUBC) [21] is applied on the top boundaries to simulate unidirectional compressive strain. All the points on a particular boundary face always remain in a parallel plane. In this case, all the nodes on the top boundary would move by the applied displacement. The nodes on the boundaries perpendicular to the applied displacement direction experience an equal lateral displacement governed by Poisson's ratio. This is also referred to as a uniform traction boundary condition. Other feasible boundaries are discussed by Sab [22]. The same methodology was implemented for particulate composites [23] with good success. The other faces of the foam are left unrestrained. Boomsma et al. [15] stated that the foam is allowed in practice [24] to expand freely in the planes transverse to the application of compressive force to maintain the isotropic nature of foams. This implies that the porosity of the foam is related to $\varepsilon$ by:

$$
\Phi_{\text {unrestrained }}=1-\frac{1-\Phi_{0}}{(1+\varepsilon)\left(1-v_{e f f} \varepsilon\right)^{2}}
$$

A similar relation was provided by Boomsma and Poulikakos [11], but it did not take into account the lateral expansion of the foam.

The foam material in the stress formulation is treated as an isotropic elastic-plastic material. To mimic the plastic behavior of the material, a very low Young's modulus is applied once the material crosses the yield strength of the bulk material. The overall behavior of the foam as an isotropic elastic-plastic material is defined by the following differential equation: 


$$
\frac{\partial}{\partial t}\left(\rho \frac{\partial w_{i}}{\partial t}\right)=\frac{\partial}{\partial}\left[\mu\left(\frac{\partial w_{i}}{\partial x_{j}}+\frac{\partial w_{j}}{\partial x_{i}}\right)\right]+\frac{\partial}{\partial x_{i}}\left(\lambda \frac{\partial w_{k}}{\partial x_{k}}\right)
$$

where $\lambda=\frac{v E}{(1+v)(1-2 v)}$ and $\mu$ are Lame's coefficients. ANSYS Mechanical [20] was used to solve this differential equation. Ten-node tetrahedral elements were used for the three-dimensional mechanical analysis. The large displacement option was turned on in ANSYS as the foam is compressed by $10 \%$ of its initial height.

Predictions of Young's modulus were made using this model as a baseline check for a range of applied strains. Figure 3 compares the stress-strain curves obtained using the $1 / 8^{\text {th }}$ unit-cell with that using the complete unit cell. The two computations yield identical values of Young's modulus, establishing that the periodicity assumption adopted here is valid.

\section{Convective Flow and Heat Transfer}

We consider a three-dimensional periodic module with a constant translational vector $(\bar{L})$ with respect to a flow direction (x-axis) as shown in Figure 4. For periodic boundaries, according to [25], the velocity and the pressure at any position $\vec{r}$ may be written as:

$$
\begin{gathered}
u_{i}(\bar{r})=u_{i}(\bar{r}+\bar{L})=u_{i}(\bar{r}+2 \bar{L})=\ldots \\
P(\vec{r})-P(\vec{r}+\vec{L})=P(\vec{r}+\vec{L})-P(\vec{r}+2 \vec{L})=\ldots
\end{gathered}
$$

It should be noted that there may be other periodic boundaries in the module, but there is no net inflow through any of these boundaries. For flow through periodic unit cells, the pressure gradient can be divided into two components: (a) periodic component, $\frac{\partial \hat{p}}{\partial x_{i}}$, and (b) a linearly varying component, $\frac{\partial \bar{p}}{\partial x_{i}} \vec{e}_{L}$, such that: $\frac{\partial P}{\partial x_{i}}=-\frac{\partial \bar{p}}{\partial x_{i}} \vec{e}_{L, i}+\frac{\partial \hat{p}}{\partial x_{i}}$ where $e_{L, i}$ is the $\mathrm{i}^{\text {th }}$ component of the unit vector in the direction $\vec{L}$.

A constant heat flux is imposed on the metal foam surfaces. For given heat-flux boundary conditions, the shape of the temperature field becomes constant from module to module. Thus, the periodic condition for temperature is given by

$$
T(\vec{r})-T_{b}(\vec{r})=T(\vec{r}+\vec{L})-T_{b}(\vec{r}+\vec{L})=T(\vec{r}+2 \vec{L})-T_{b}(\vec{r}+2 \vec{L})=\ldots
$$

Here, the bulk temperature $T_{b}$ is defined as

$$
\frac{\iint_{A}\left|u_{i} e_{L, i}\right| T d A}{\iint_{A}\left|u_{i} e_{L, i}\right| d A}=0
$$


where $\mathrm{A}$ is the area of cross-section. The governing flow and heat transfer equations for laminar, periodic, fully developed, incompressible, steady flow of a Newtonian fluid are [25, 26]:

$$
\begin{gathered}
\frac{\partial}{\partial x_{i}}\left(\rho u_{i}\right)=0 \\
\frac{\partial}{\partial x_{i}}\left(\rho u_{i} u_{j}\right)=-\frac{\partial \hat{p}}{\partial x_{i}}+\frac{\partial}{\partial x_{i}}\left(\mu \frac{\partial u_{i}}{\partial x_{j}}\right)_{i}-\frac{\partial \bar{p}}{\partial x_{i}} \vec{e}_{L, i} \\
\frac{\partial}{\partial x_{i}}\left(\rho u_{i} C_{P} T\right)=\frac{\partial}{\partial x_{i}}\left(k \frac{\partial T}{\partial x_{i}}\right)
\end{gathered}
$$

Though the current study considers only the laminar flow condition, it can easily be extended to fully

developed turbulent regimes. In Eq. (5), the terms involving $\partial^{2} / \partial x^{2}$ have been included to account for the large local streamwise gradients that may occur in periodically fully developed flows. The $\frac{\partial \bar{p}}{\partial x_{i}}$ term in Eq. (5) is assigned a priori, and controls the mass flow rate through the module, and hence, the pore Reynolds number. A no-slip boundary condition is imposed for the velocities on the bounding walls. Details of the mathematical model are available in [15, 25], while the numerical methods for periodic flow on unstructured meshes along with the implementation are outlined in [26].

The various periodic unit cell geometries used in this work were created using the commercial software GAMBIT [27]. The geometry was discretized into three-dimensional finite volumes using hybrid (tetrahedral and hexagonal) elements in GAMBIT by specifying the minimum edge length. The finite volume mesh so created was exported to the commercial code FLUENT [28] for flow simulations. A second-order upwind scheme was used for the convective calculations. A co-located pressure-velocity formulation in conjunction with the SIMPLE algorithm was used for obtaining the velocity fields, and the linearized systems of equations solved using an algebraic multigrid algorithm. Details of the numerical method may be found in [29]. The calculations were terminated when the (scaled) residuals [28] had dropped below $10^{-6}$ for all governing equations.

Grid-independence tests were performed using the procedures detailed in [15]. The calculations reported in this paper were performed using approximately 200,000 cells.

\section{Coupling Methodology}

One-way coupling is established between ANSYS and FLUENT to solve for flow through compressed foams. The coupling scheme is illustrated graphically in Figure 5. The solid and fluid parts of the unit cell are meshed at the same time in GAMBIT so that the nodes at the solid/liquid interface 
match. The structural compression of the foam is modeled in ANSYS. The nodal displacements of the solid/liquid surface are extracted and fed into FLUENT. Custom user-defined functions (UDFs) are written utilizing the dynamic remeshing capabilities in FLUENT to remesh the FLUENT mesh to match the interface node displacement obtained from the ANSYS compression model. The new compressed mesh is used to predict the convective flow characteristics of the compressed foams.

\section{RESULTS}

The BCC, FCC and A15 lattice foam geometries are structurally compressed and the effective Young's modulus is predicted for different porosities. The geometry which best matches the experimentally measured values of Young's modulus of open-celled foams is chosen as the structure for further study of the effect of compression on convective flow and heat transfer characteristics.

\section{Effective Young's Modulus Prediction}

Different $1 / 8^{\text {th }}$ foam geometries were constructed for various porosities based on the BCC, FCC, and A15 structures. Sample $1 / 8^{\text {th }}$ foam geometries corresponding to each unit cell are shown in Figure 6 . The foam geometries were tested under uniaxial compression and the effective Young's modulus $\left(E_{\text {eff }}\right)$ was calculated as:

$$
E_{\text {eff }}=\frac{P_{t o p}}{\left(\delta_{t o p} / 0.5\right)}
$$

where $P_{t o p}$ is the pressure applied on the top surface and $\delta_{t o p}$ is the displacement of the top surface. The factor of 0.5 results from the use of the $1 / 8^{\text {th }}$ unit-cell foam geometry. The predicted effective Young's modulus based on the three foam structures is compared with experimental measurements of Young's modulus of various metal open-celled foams [9, 30, 31, 32] in Figure 7.

Also shown in Figure 7 is the Gibson and Ashby theoretical model [33] given by

$$
E_{\text {eff }} / E_{\text {solid }}=\left(\rho_{\text {eff }} / \rho_{\text {solid }}\right)^{2}
$$

In this model, the foam was considered to be composed of tetrakaidecahedral unit cells with ligaments of uniform cross-section. The bending of the members was considered to be the primary mechanism for compression. It can be seen from the figure that the A15 and the FCC models provide the best match to experimental results. The A15 model is seen to follow the square law of the Gibson and Ashby model.

It was shown by Krishnan et al. [34] that the A15 and the BCC unit cells are most capable of representing the flow characteristics of foams. Since the A15 structure yields good predictions for both structural deformation and fluid flow, it is chosen for prediction of the convective flow characteristics of compressed foams in the following sections. 


\section{Model Validation - Permeability of Polyurethane Foams}

The benchmark problem considered for validating the coupled model is the prediction of permeability of polyurethane foams under uniaxial compression with sides restrained [7]. The polyurethane foam in the experiments is of $97 \%$ porosity. An A15 model with $97.3 \%$ porosity was generated. The mechanical properties of polyurethane used for the numerical compression are listed in Table 1. The foams are compressed in ANSYS with the sides restrained to match the experimental conditions. As the sides are restrained, the effective Poisson's ratio of the foam $v_{\text {eff }}$ is zero and hence the porosity of the restrained foam is given by:

$$
\Phi_{\text {restrained }}=1-\frac{1-\Phi_{0}}{(1+\varepsilon)}
$$

In the experiments, Dawson et al. [7] compressed the foams unidirectionally keeping the other sides restrained. Creeping flow experiments, with flow parallel to the direction of compression were conducted with water as the fluid and the permeability determined based on the Darcy's Law.

As mentioned earlier, the cells in polyurethane foams collapse due to buckling of the ligaments. This occurs at approximately $7.5 \%$ compression [7]. The normalized permeability of compressed foams from the experiments is compared in Figure 8 to numerical results from the present work for compressions less than the buckling compression (7.5\%). The models of Gent and Rusch [4], Hilyard and Collier [5] and Dawson et al. [7] are also shown for comparison. The deviations between the models and the experimental results for normalized permeability are shown in.Table 2. Also included in the table are the model equations, and the normalized permeabilities predicted at $\varepsilon=7.5 \%$. The experimental value at this compression level is 0.893 . The numerical results are seen to be in good agreement with the experimental results, with the deviation being within $3 \%$.

\section{Aluminum Foams}

With the numerical methodology validated above, the model is applied to the prediction of permeability in compressed aluminum foams. Two A15 foam porosities of $\Phi_{0}=0.79$ and 0.94 (precompression values) are considered. The flows in both the direction of compression and in the transverse direction are studied.

\subsubsection{Permeability}

It has been observed [9] that plastic collapse in aluminum foams occurs at $\sim 12 \%$ compression. Due to numerical difficulties, the two aluminum foams are compressed within the elastic range and into the elastic-plastic range with compressions of 1,2,3,6 and 10\%. The mechanical properties of aluminum 
used for the numerical compression are listed in Figure 8. Sample $1 / 8^{\text {th }}$ unit-cell grids for the two porosities at two levels of compression are shown in Figure 9. The outline of the uncompressed shape of the foam is also shown in the figure. The two levels of compression shown in the figure (3\% and $10 \%)$ are chosen so that the foam is elastic at the lower compression level and elastic-plastic at the higher compression level. As the foam is allowed to expand laterally during compression, the porosity change is not appreciable during elastic compression. At the $10 \%$ compression level, the porosity was found to change from $\Phi_{0}=0.79$ to $\Phi=0.77$ and $\Phi_{0}=0.94$ to $\Phi=0.93$. The present simulation thus mainly captures the effect of the change in pore shape upon compression.

Figure 10 shows the normalized values of permeability for the two foams at different compressions; the initial state is uncompressed. The permeability of the foam is calculated using $K=-\left(\mu u_{\text {mean }}\right) /\left(\partial \bar{p} / \partial x_{i}\right)$, where $u_{\text {mean }}$ is obtained for the specified inlet mass flow rate in the Darcy regime $(\operatorname{Re}<10)$ and is normalized by the uncompressed-foam permeability. The $\|$ symbol corresponds to the case where the flow is parallel to the direction of compression, while the $\perp$ symbol indicates the flow direction being transverse to the compression direction. The available theoretical correlations from the literature $[4,5,7]$ are also plotted in the figure. The approximate Hilyard and Collier model shown represents $\mathrm{K} / \mathrm{K}_{0}=(1+2 \varepsilon)$, as shown in Table 2. As mentioned before, the Dawson et al. [7] model is for the parallel flow direction. Experimental data for metal foams in this elastic-plastic range before complete cell collapse appear to be unavailable.

The flow direction with respect to the direction of compression is clearly important in determining permeability. The permeability for flow in the transverse direction is higher than for flow in the parallel direction. For aluminum foams, the Hilyard and Collier model [5] provides the best prediction of permeability for parallel flow, while the Gent and Rusch model [4] agrees best with the permeability variation in transverse flow.

When the pressure drop and the flow rate are plotted in normalized terms as the friction factor versus Reynolds number based on permeability, all the cases in Figure 10 collapse onto the respective uncompressed cases (Figure 11). The Reynolds number and friction factor in the figure are defined as $\operatorname{Re}_{K}=\rho u_{\text {mean }} \sqrt{K} / \mu$ and $f_{K}=(d p / d x) \sqrt{K} / \rho u_{\text {mean }}^{2}$, respectively. As was reported by Krishnan et al. [34] for uncompressed foams, the predicted friction factors compare well with the experimental correlations for $\Phi_{0}=0.94$, while the results deviate for $\Phi_{0}=0.79$.

\section{$\underline{\text { Heat Transfer }}$}

Heat conduction through the foam ligaments is not modeled in this analysis since a constant heat flux boundary condition is imposed on the ligament walls for the prediction of friction factor and Nusselt 
number. If constant temperature boundary conditions were employed on the foam walls, the predicted Nusselt numbers would be somewhat different from those predicted here [25].

The Nusselt number is defined as:

$$
N u_{D}=\frac{h D}{k_{f}}=\frac{q " D}{k_{f}\left(\bar{T}_{s}-T_{b}\right)}
$$

In the above equation, $\bar{T}_{s}$ is the averaged temperature of the foam. In Figure 12, the predicted local Nusselt number $\left(N u_{D}\right)$ is plotted as a function of $\left(P e_{D} /(1-\Phi)\right)^{1 / 2}$. Also plotted are the experimental results from Calmidi and Mahajan [38]. The x-axis scale is obtained by balancing the convective and axial diffusive fluxes. Transverse compression is shown to increase heat transfer. The parallel direction sees the opposite effect.

As with friction factor, when the Nusselt number $\left(N u_{K}\right)$ and modified Peclet number $\left(P e_{K} /(1-\Phi)\right)^{1 / 2}$ are non-dimensionalized with $\sqrt{K}$ as length scale, the lines collapse onto the uncompressed case (Figure 13).

\section{Effective Thermal Conductivity}

The numerical results for effective thermal conductivity for an aluminum-air system are considered first. The solid and liquid domains of the foam are deformed for the effective thermal conductivity calculations using the coupled model described previously. The effective thermal conductivity is computed by numerically solving for the conduction heat transfer through both the metal foam and the interstitial fluid on a single periodic module. A given heat flux condition is not employed as was done in the Nusselt number calculations above; instead, continuity of temperature and heat flux are employed as the interfacial conditions. Under the periodicity assumption, each module in the heat flow direction experiences an identical temperature drop. Computations are performed on a periodic module by imposing an arbitrary temperature drop $\Delta T$ across the periodic module along the heat flow direction. The resulting heat transfer rate at the periodic boundaries is used to obtain the effective thermal conductivity of the system using the relation:

$$
k_{\text {eff }}=\frac{-\int_{A_{P}} J \cdot d A}{\Delta T A_{P}}
$$

where $J$ is the diffusion flux vector at the periodic face, $d A$ is the outward pointing elemental face area vector on the periodic face, and $A_{P}$ is the area of the periodic face. Calculations are performed using a modified version of the commercial code FLUENT [28]. Details of the mathematical model and numerical method are outlined in $[15,35]$. The calculations are performed for a temperature difference imposed both in the parallel and in the transverse direction. 
Figure 14 summarizes the calculated effective thermal conductivity for the compressed aluminum foam-air system as a function of foam porosity. Also plotted in the figure are the predictions from the available numerical and semi-empirical models and experimental measurements from the literature for uncompressed open-celled foams $[36,37,38,39,40]$. The available experimental effective thermal conductivity measurements for foams cover a porosity range of $0.89<\varepsilon<0.98$. Paek et al. [37] and Calmidi and Mahajan [38] reported respective experimental uncertainties of $12 \%$ and $3.6 \%$ for their measurements. Also plotted is the theoretical result from Lemlich's original work on electrical conductivity of liquid foams [40]. Using a direct analogy between Ohm's law and Fourier's law, we adopt his results for effective thermal conductivity of metal foams $\left(k_{\text {eff }}=k_{s} \frac{(1-\Phi)}{3}\right)$. Details of the Lemlich theory and its implications are discussed in [40]. The conductivity results are difficult to analyze when compared as a function of porosities. Hence we next consider the conductivity of compressed foams with respect to their individual uncompressed cases.

Figure 15 shows the normalized conductivity of compressed foams as a function of foam compression. The conductivity of the compressed foam $\left(k_{\text {eff }}\right)$ is normalized by the conductivity of the uncompressed foam $\left(k_{0}\right)$. The transverse thermal conductivity increases with an increase in compression whereas the parallel conductivity is seen to decrease with an increase in compression. One possible explanation for this observation is as follows. The majority of heat flows through the aluminum ligaments. Therefore, the change in the shape of the ligaments with compression determines whether the conductivity increases or decreases. The ligaments of the foam vary in cross-sectional area, with the thinnest part offering the greatest resistance. A compression along the axis of a ligament worsens this constriction, resulting in a decrease in thermal conductivity. Hence the conductivity parallel to the direction of compression decreases. Based on a similar argument, the ligaments in the transverse direction experience an expansion consistent with Poisson's ratio and offer reduced constriction resistance and increased thermal conductivity due to the compression in this direction.

The effect of the saturating fluid properties is seen by comparing aluminum foam-air and aluminum foam-water systems (Figure 16). The more conductive fluid (water) slightly decreases the effect of compression. In general, however, compression in the range considered here has only a small effect on the effective thermal conductivity.

The effect of compression on the thermal conductivity has been small within the range of compressions simulated; a compression of $10 \%$ led to $8 \%$ maximum change in effective conductivity (Figure 15). In practice, the foams are generally crushed, breaking the ligaments in the process. This 
results in a decrease in effective conductivity due to contact resistance at the broken ends, an effect not captured in our simulations.

\section{CORRECTED GENT AND RUSCH MODEL}

As mentioned previously, Gent and Rusch [4] modeled the foam as an array of circular tubes. The effective diameter relation, given by $d=d_{0}(1+\mathcal{\varepsilon})^{1 / 2}$, is appropriate for flow, transverse to the compression direction. The permeability of the foam was given by Gent and Rusch [4] as a function of diameter to be:

$$
K=A d^{2}
$$

where A is an empirical constant. Gent and Rusch did not consider the effect of lateral expansion while calculating the effective diameter of compressed foams. To improve on this model for transverse flow, we suggest a correction to the model. Including the Poisson effect, the effective diameter is given by a change in effective volume as:

$$
d=d_{0}\left[(1+\varepsilon)\left(1-v_{e f f} \mathcal{E}\right)^{2}\right]^{1 / 2}
$$

Substituting the effective diameter into the permeability relation gives:

$$
K / K_{0}=\left[(1+\varepsilon)\left(1-v_{e f f} \varepsilon\right)^{2}\right]
$$

where $K_{0}$ is the permeability of the uncompressed foam. The high porosity approximation of the corrected model is given by:

$$
K / K_{0} \sim 1+\left(1-2 v_{\text {eff }}\right) \mathcal{\varepsilon}
$$

Figure 17 demonstrates the effectiveness of this correction. The corrected model improves on the original Gent and Rusch model in predicting the permeability in transverse flow.

\section{CONCLUSIONS}

A model which couples structural deformation with fluid flow and heat transfer computations has been developed to predict the permeability of compressed metal foams. Three different foam unit cell models, BCC, FCC and A15 are considered. The A15 model predicts both the compressive response and the fluid flow in uncompressed foams well. Predictions of permeability as a function of compression using the A15 model are validated against experimental results [7]. The model is then applied to the prediction of permeability of aluminum foams. The Hilyard and Collier model [5] is found to yield reasonable predictions of permeability for flow parallel to the direction of compression. A correction to the Gent and Rusch model [4] is proposed to better predict the permeability of flow in the direction transverse to the compression direction. Compression of foams increases the transverse heat transfer and reduces parallel 
heat transfer. The effect of compression is to increase the transverse conductivity and reduce parallel conductivity.

\section{ACKNOWLEDGEMENT}

The authors acknowledge financial support from industry members of the Cooling Technologies Research Center, an NSF Industry/University Cooperative Research Center.

\section{REFERENCES}

[1] M. F. Ashby, A. Evans, N. A. Fleck, L. J. Gibson, J. W. Hutchinson, and H. J. G. Wadley, Metal Foams: A Design Guide, Butterworth - Heinemann, Boston, 2000.

[2] T. J. Lu, H. A. Stone, and M. F. Ashby, Heat transfer in open-cell metal foams, Acta Materialia, vol. 46, pp. 3619 - 3635, 1998.

[3] B. Ozmat, B. Leyda, and B. Benson, Thermal applications of open-cell metal foams, Materials and Manufacturing Processes, vol. 19, pp. 839 - 862, 2004.

[4] A. N. Gent, and K. C. Rusch, Permeability of open-cell foamed materials, Journal of Cellular Plastics, vol. 2, pp. 46-51, 1966.

[5] N. C. Hilyard, and P. Collier, A structural model for air flow in flexible PUR foams, Cell. Polym., vol. 9, pp. 219-225, 1987.

[6] N. J. Mills, and G. Lyn, Modelling of Air Flow in Impacted Polyurethane foam, Cellular Polymers, vol. 21(5), pp. 343-367, 2002.

[7] M. A. Dawson, J. T. Germaine, and L. J. Gibson, Permeability of open-cell foams under compressive strain, International Journal of Solids and Structures, vol. 44, pp. 5133-5145, 2007.

[8] G. D. A. von der Schulenburg, M. Paterson-Beedle, L. E. Macaskie, L. F. Gladden, and M. L. Johns, Flow through an evolving porous media - compressed foam, Journal of Material Science, vol. 42, pp. 6541-6548, 2007.

[9] Y. W. Kwon, R. E. Cooke, and and C. Park, Representative unit-cell models for open-cell metal foams with or without elastic filler, Mater. Sci. Eng. A, vol. 343, pp. 63-70, 2003.

[10] N. Dukhan, R. Picón-Felicano, and Á. R. Álvarez-Hernández, Air flow through compressed and uncompressed foams: Measurements and correlations, Journal of Fluids Engineering, vol. 128, pp. 1004-1012, 2006.

[11] K. Boomsma, and D. Poulikakos, The effect of compression and pore size variations on the liquid flow characteristics in metal foams, Journal of Fluids Engineering, vol. 124, pp. 263-272, 2002. 
[12] J. J. Hwang, G. J. Hwang, R. H. Yeh, and C. H. Chao, Measurement of interstitial convective heat transfer and frictional drag for flow across metal foams, ASME J. Heat Transfer, vol. 124, pp. 120-129, 2002.

[13] K. Boomsma, D. Poulikakos, and F. Zwick, Metal foams as compact high performance heat exchangers, Mechanics of Materials, vol. 35, pp. 1161-1176, 2003.

[14] J. Kein, G. Gilchrist, J. Karanik, N. Arcas, R. Yurman, J. Whiteside, B. Shields, and T. Bartilucci. Thermal management of airborne early warning and electronic warfare systems using foam metal fins, Proceedings of IPACK03, Hawaii, USA, 2003.

[15] S. Krishnan, J. Y. Murthy, and S. V. Garimella, Direct simulation of transport in open-cell metal foam, ASME Journal of Heat Transfer, vol. 128, pp. 793-799, 2006.

[16] R. Phelan, D. Weaire, and K. Brakke, Computation of equilibrium foam structures using the Surface Evolver, Experimental Mathematics, vol. 4, pp. 181-192, 1995.

[17] D. Weaire, A philomorph looks at foam, Proceedings of the American Philosophical Society, vol. 145, pp. 564-574, 2001.

[18] K. P. Dharmasena, and H. N. G. Wadley, Electrical conductivity of open-cell metal foams, Journal of Materials Research, vol. 17, pp. 625-631, 2002.

[19] K. Boomsma, D. Poulikakos, and Y. Ventikos, Simulations of flow through open cell foams using an idealized periodic cell structure, International Journal of Heat and Fluid Flow, vol. 24, pp. 825834, 2003.

[20] ANSYS 8.1 User Manual, ANSYS, Inc., Canonsburg, Pennsylvania, 2004.

[21] T. Kanit, S. Forest, I. Galliet, V. Mounoury, and D. Jeulin, Determination of the size of the representative volume element for random composites: statistical and numerical approach, International Journal of Solids and Structures, vol. 40, pp. 3647-3679, 2003.

[22] K. Sab, On the homogenization, the simulation of random materials, European Journal of Mechanics - A/Solids, vol. 11, pp. 585-607, 1992.

[23] S. R. Annapragada, D. Sun, and S. V. Garimella, Prediction of effective thermo-mechanical properties of particulate composites, Computational Materials Science, vol. 40(2), pp. 255-256, 2007.

[24] ERG, Duocel Aluminum Foam Data Sheet, ERG Material and Aerospace, Oakland, 1999.

[25] S. V. Patankar, C. H. Liu, and E. M. Sparrow, Fully developed flow and heat transfer in ducts having streamwise-periodic variations of cross-sectional area, ASME Journal of Heat Transfer, vol. 99, pp. 180-186, 1977. 
[26] J.Y. Murthy, and S. Mathur, Periodic flow and heat transfer using unstructured meshes, International Journal of Numerical Methods in Fluids, vol. 25, pp. 659-677, 1997.

[27] Fluent Inc., User's Guide for GAMBIT 2.3, 2006.

[28] Fluent Inc., User's Guide for FLUENT 6.3, 2006.

[29] S. R. Mathur, and J. Y. Murthy A pressure-based method for unstructured meshes, Numerical Heat Transfer: Part B, vol. 31, pp. 195-216, 1997.

[30] H. Bart-Smith, A. F. Bastawros, D. R. Mumm, A. G. Evans, D. J. Sypeck, and H. N. G. Wadley, Compressive deformation and yielding mechanisms in cellular $\mathrm{Al}$ solids determined using X-ray tomography and surface strain mapping, Acta Mater., vol. 46(10), pp. 3583-3592, 1998.

[31] E. W. Andrews, W. Sanders, and L. J. Gibson, Compressive and tensile behavior of aluminum foams, Mater. Sci. Eng. A, vol. 270, pp. 113-124, 1999.

[32] P. S. Dubbelday, Poisson's ratio of foamed aluminum determined by laser Doppler vibrometry, J. Acoust. Soc. Am., vol. 91(3), pp. 1737-44, 1992.

[33] L. J. Gibson, and M. F. Ashby, Cellular solids: Structure and Properties, Cambridge University Press; 1997.

[34] S. Krishnan, S. V. Garimella, and J. Y. Murthy, Simulation of thermal transport in open-cell metal foams: effect of periodic unit cell structure, ASME Journal of Heat Transfer, vol. 130, pp. 1-5, 2008.

[35] S. Kumar, and J. Y. Murthy, A numerical technique for computing effective thermal conductivity of fluid-particle mixtures, Numerical Heat Transfer: Part B, vol. 47, pp. 555-572, 2005.

[36] A. Bhattacharya, A. A. Calmidi, and R. L. Mahajan, Thermophysical properties of high porosity metal foams, International Journal of Heat and Mass Transfer, vol. 45, pp. 1017-1031, 2002.

[37] J. W. Paek, B. H. Kang, S. Y. Kim, and J. M. Hyun, Effective thermal conductivity and permeability of aluminum foam materials, International Journal of Thermophysics, vol. 21, pp. $453-464,2000$.

[38] V. V. Calmidi, and R. L. Mahajan, The effective thermal conductivity of high porosity fibrous metal foams, ASME Journal of Heat Transfer, vol. 121, pp. 466 - 471, 1999.

[39] K. Boomsma, and D. Poulikakos, On the effective thermal conductivity of a three-dimensionally structured fluid-saturated metal foam, International Journal of Heat and Mass Transfer, vol. 44, pp. $827-836,2001$.

[40] R. Lemlich, A theory for the limiting conductivity of polyhedral foam at low density, Journal of Colloid and Interface Science, vol. 64, pp. 107-110, 1978. 
Table 1. Mechanical properties of materials used.

\begin{tabular}{|c|c|c|}
\hline & Polyurethane & Aluminum \\
\hline Young's modulus (MPa) & 25 & 72,000 \\
\hline Poisson ratio & 0.49 & 0.3 \\
\hline Yield Strength (MPa) & 30 & 1296 \\
\hline
\end{tabular}


Table 2. Deviation of various models from experiments.

\begin{tabular}{|c|c|c|c|}
\hline Model & Equation for $\left(\mathrm{K} / \mathrm{K}_{0}\right)$ & $\begin{array}{c}\text { Maximum } \\
\text { Deviation }(\%)\end{array}$ & $\begin{array}{c}\mathrm{K} / \mathrm{K}_{0} \text { for } \\
\varepsilon=7.5 \%\end{array}$ \\
\hline Numerical & - & $3 \%$ & 0.865 \\
\hline Gent and Rusch [4] & $1+\varepsilon$ & $4 \%$ & 0.916 \\
\hline Hilyard and Collier [5] & $(1+\varepsilon)^{2}\left(\frac{1+\varepsilon-\Phi_{0}}{(1+\varepsilon)\left(1-\Phi_{0}\right)}\right)^{3}$ & $5 \%$ & 0.925 \\
\hline Dawson et al. [7] & $(1+2 \varepsilon)$ for high porosity & $2 \%$ & 0.850 \\
\hline
\end{tabular}




\section{Figure captions}

Figure 1. (a) Schematic representation of foam geometry creation, and (b) sample images of foam geometry created for BCC, FCC, and A15 arrangements of spherical pores [15].

Figure 2. $1 / 8^{\text {th }}$ foam geometry and corresponding periodic implementation for mechanical compression. Also shown is the expected compressed foam envelope (dashed lines).

Figure 3. Stress-strain relationship for unit cell and $1 / 8^{\text {th }}$ unit cell.

Figure 4. Schematic illustration of a periodic domain [15].

Figure 5. Flow chart of the coupling methodology.

Figure 6. Unit cell structures and their corresponding $1 / 8^{\text {th }}$ foam geometries.

Figure 7. Effective Young's modulus versus effective solid foam density.

Figure 8. Normalized permeability versus strain for polyurethane foam $\left(\Phi_{0}=0.97\right)$.

Figure 9. $1 / 8^{\text {th }}$ foam geometries at two compression levels ( $3 \%$ and $\left.10 \%\right)$ : (a) $\Phi_{0}=0.79$ and (b) $\Phi_{0}=$ 0.94. Uncompressed shape is shown in outline.

Figure 10. Normalized permeability versus strain for aluminum foams.

Figure 11. Predicted friction factor versus modified Reynolds number for two base foam porosities $\left(\Phi_{0}\right.$ $=0.79$ and 0.94$)$ and 4 different compressions $(\varepsilon=0.01,0.02,0.03,0.1)$.

Figure 12. Nusselt number $\left(\mathrm{Nu}_{\mathrm{D}}\right)$ variation with modified Peclet number $\left(\mathrm{Pe}_{\mathrm{D}}\right)$ for two base foam porosities $\left(\Phi_{0}=0.79\right.$ and 0.94$)$ at different compressions $(\varepsilon=0.01,0.02,0.03,0.1)$.

Figure 13. Nusselt number $\left(\mathrm{Nu}_{\mathrm{K}}\right)$ variation with modified Peclet number $\left(\mathrm{Pe}_{\mathrm{K}}\right)$ for two base foam porosities $\left(\Phi_{0}=0.79\right.$ and 0.94$)$ at different compressions $(\varepsilon=0.01,0.02,0.03,0.1)$.

Figure 14. Predicted effective conductivity $(k)$ of compressed aluminum foam-air system for two different porosities. Also plotted are available numerical, semi-empirical models and experimental measurements.

Figure 15. Normalized effective conductivity $\left(\mathrm{k} / \mathrm{k}_{0}\right)$ for the aluminum foam-air system as a function of foam compression.

Figure 16. Normalized effective conductivity $\left(\mathrm{k} / \mathrm{k}_{0}\right)$ of aluminum foam-air and aluminum foam-water systems as a function of compression.

Figure 17. Normalized permeability versus strain in the transverse flow direction. 


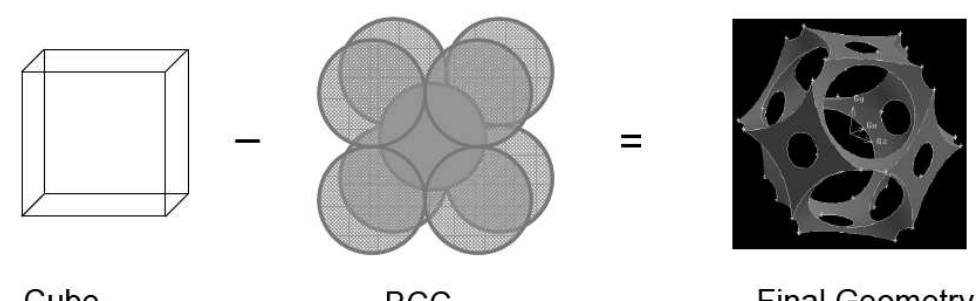

(a)

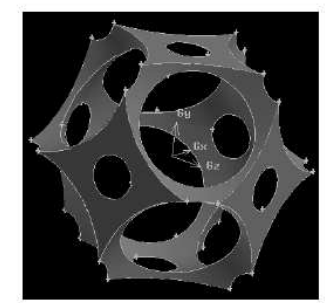

BCC

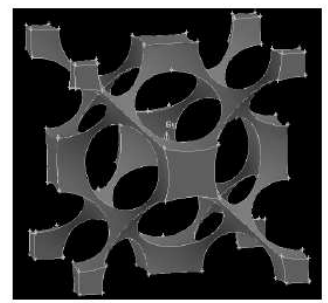

FCC

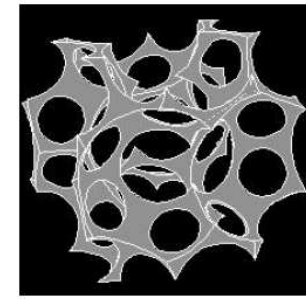

A15

Figure 1. (a) Schematic representation of foam geometry creation, and (b) sample images of foam geometry created for BCC, FCC, and A15 arrangements of spherical pores [15]. 


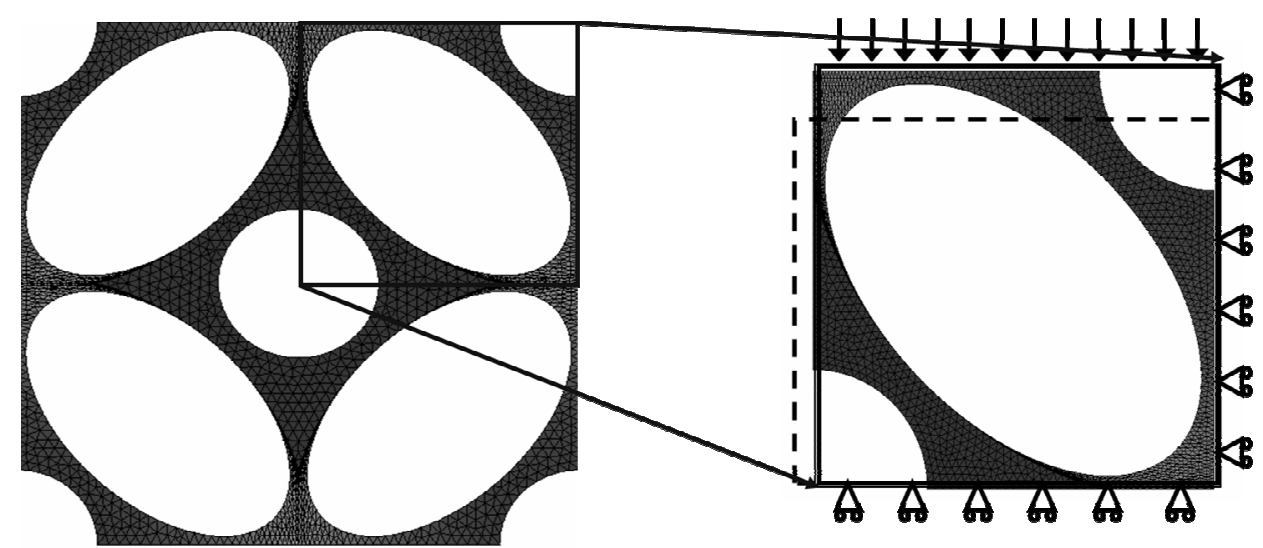

Figure 2. $1 / 8^{\text {th }}$ foam geometry and corresponding periodic implementation for mechanical compression. Also shown is the expected compressed foam envelope (dashed lines). 


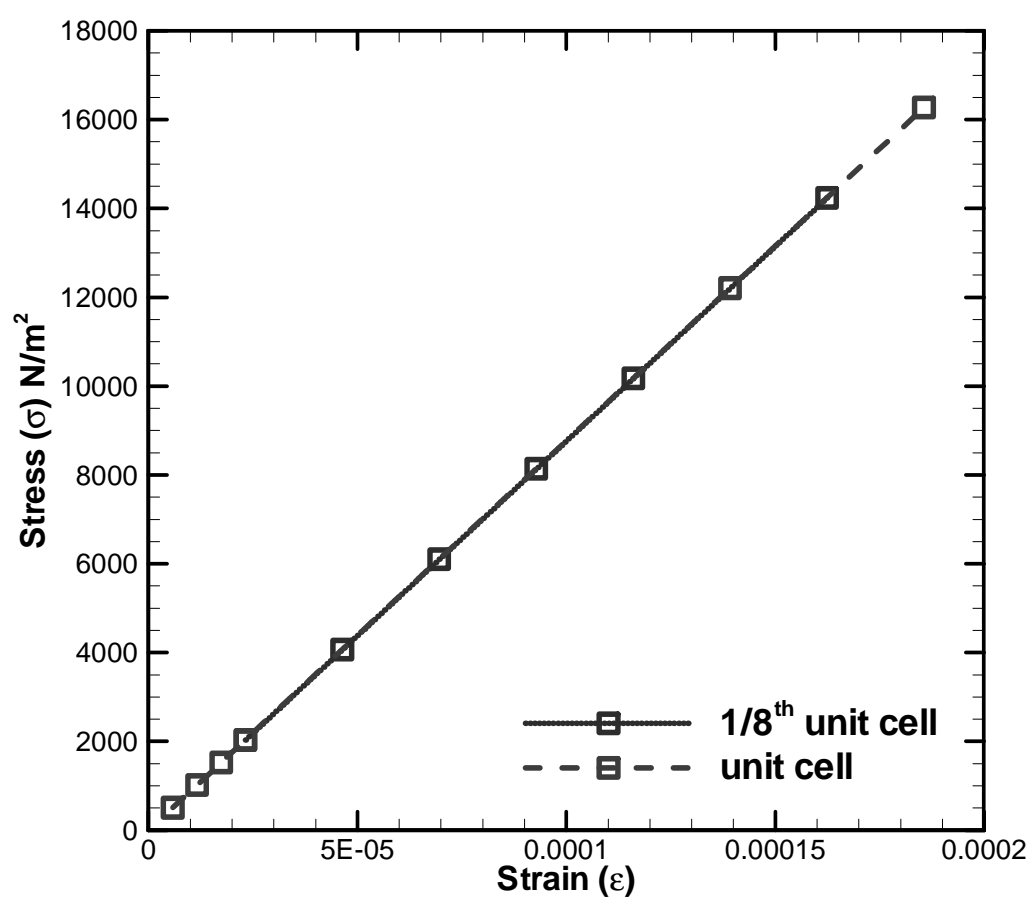

Figure 3. Stress-strain relationship for unit cell and $1 / 8^{\text {th }}$ unit cell. 


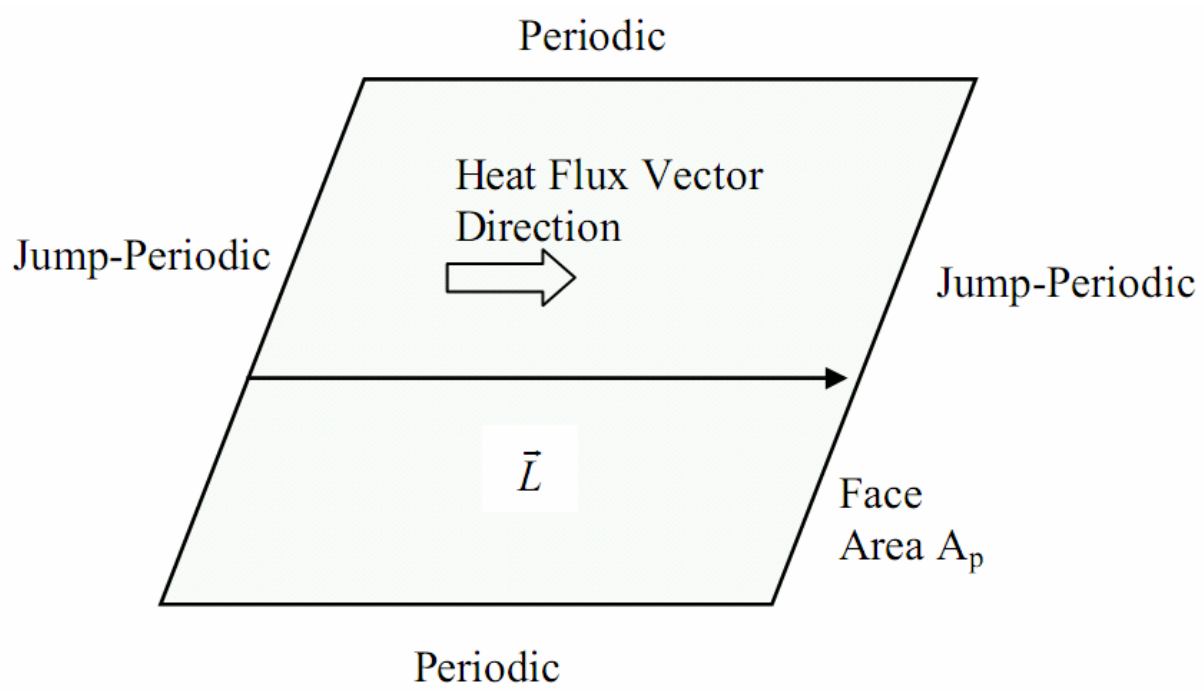

Figure 4. Schematic illustration of a periodic domain [15]. 


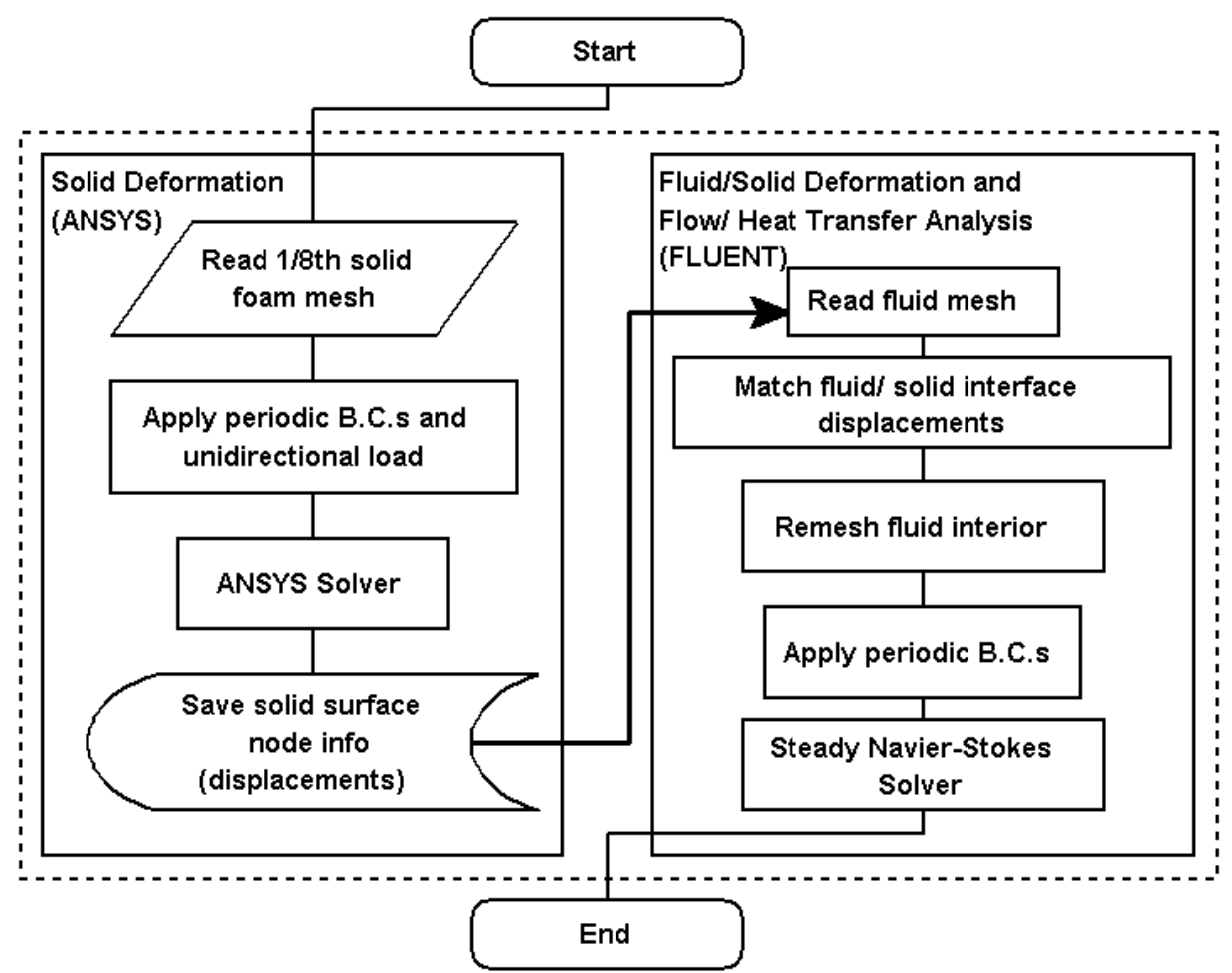

Figure 5. Flow chart of the coupling methodology. 


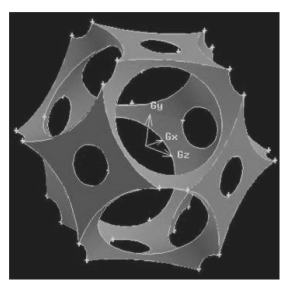

BCC Model

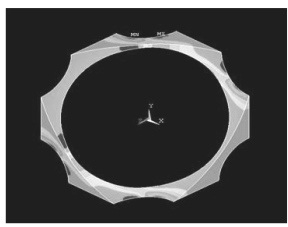

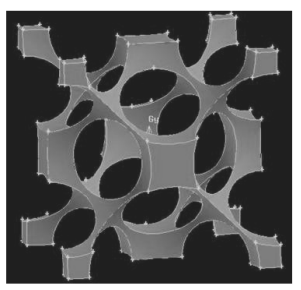

FCC Model

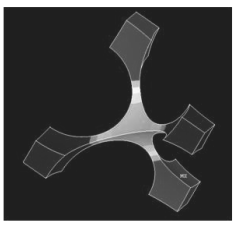

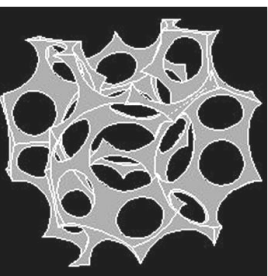

A15 Model

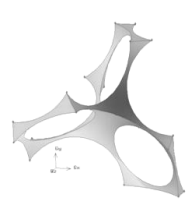

Figure 6. Unit cell structures and their corresponding $1 / 8^{\text {th }}$ foam geometries. 


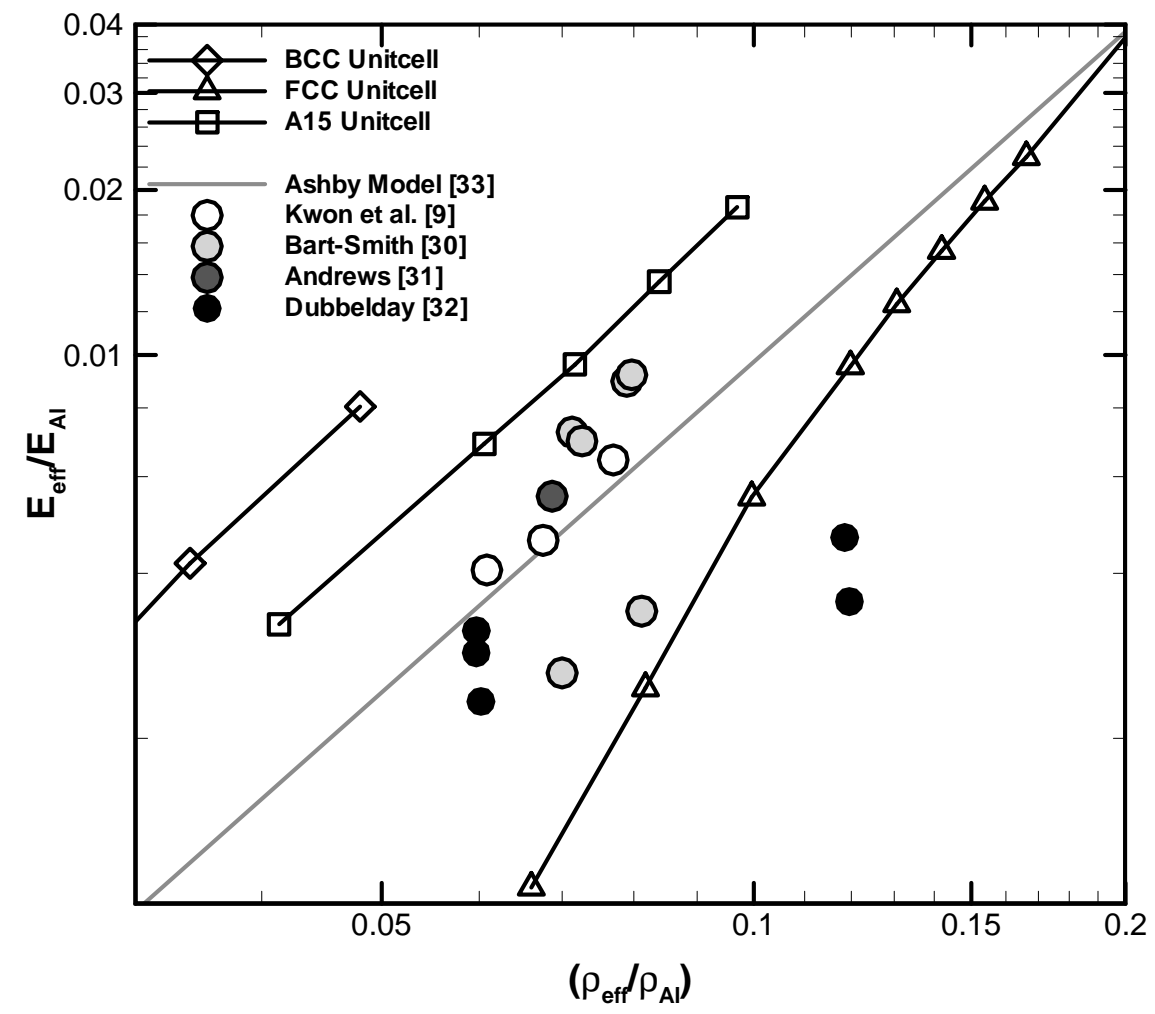

Figure 7. Effective Young's modulus versus effective solid foam density. 


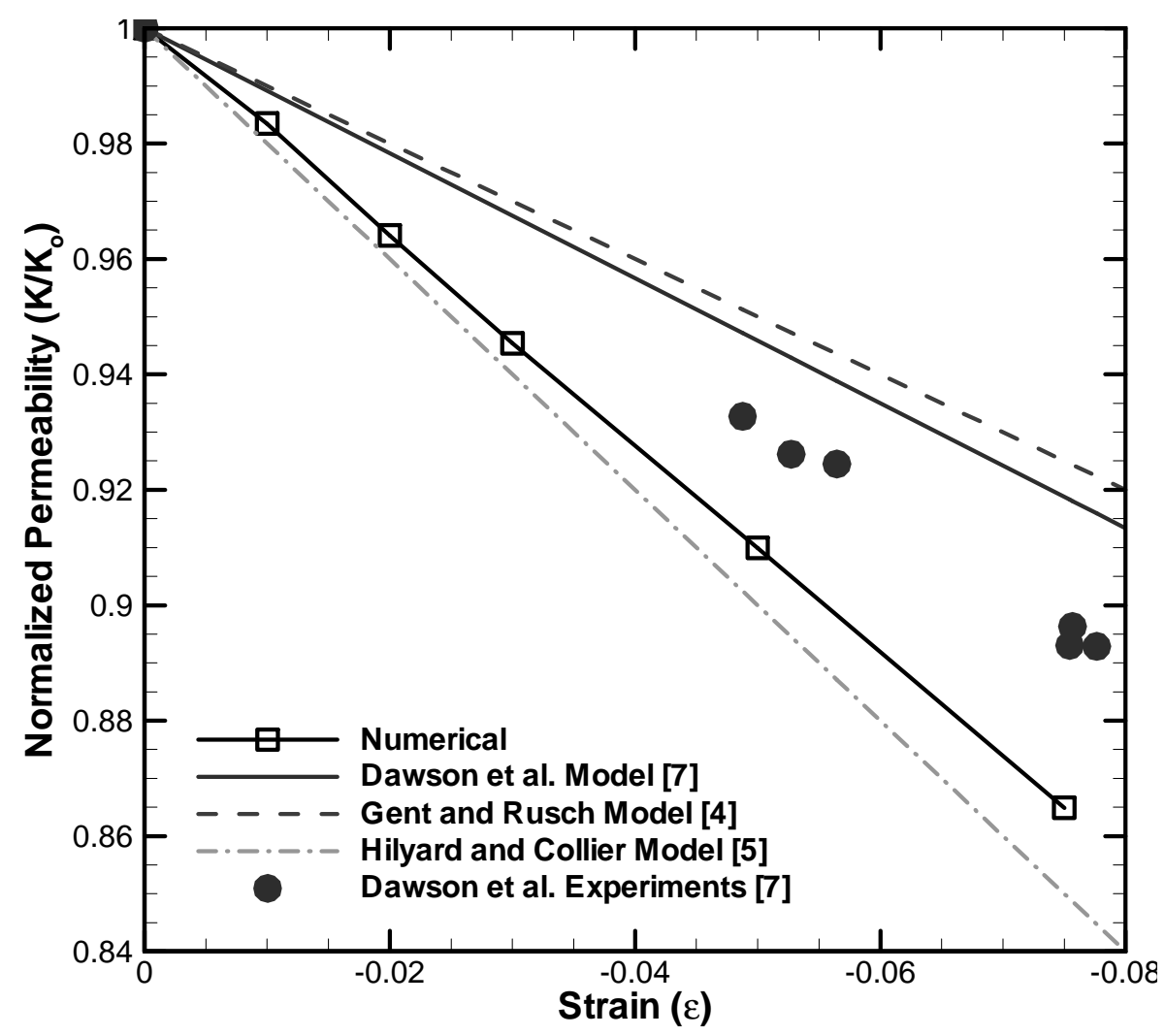

Figure 8. Normalized permeability versus strain for polyurethane foam $\left(\Phi_{0}=0.97\right)$. 

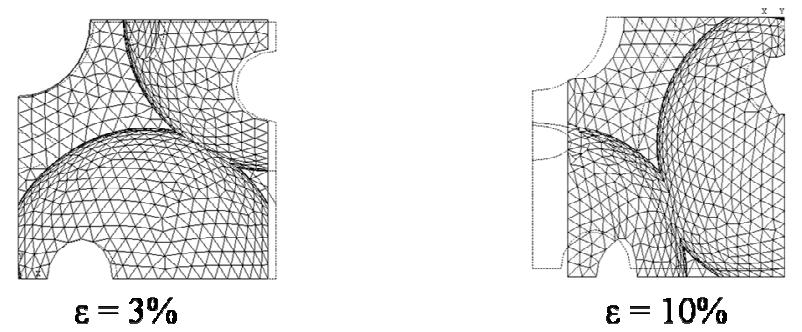

(a)
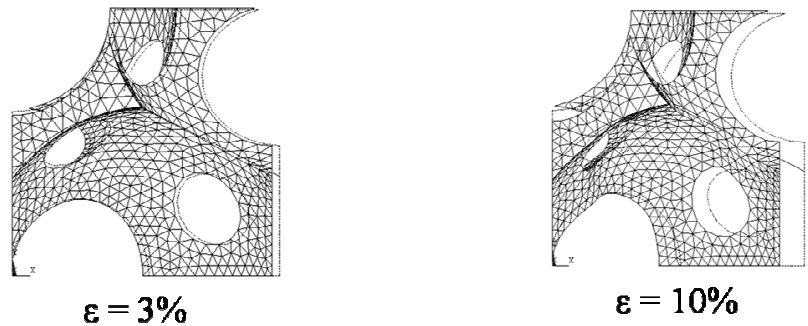

(b)

Figure 9. $1 / 8^{\text {th }}$ foam geometries at two compression levels ( $3 \%$ and $10 \%$ ): (a) $\Phi_{0}=0.79$ and (b) $\Phi_{0}=$ 0.94. Uncompressed shape is shown in outline. 


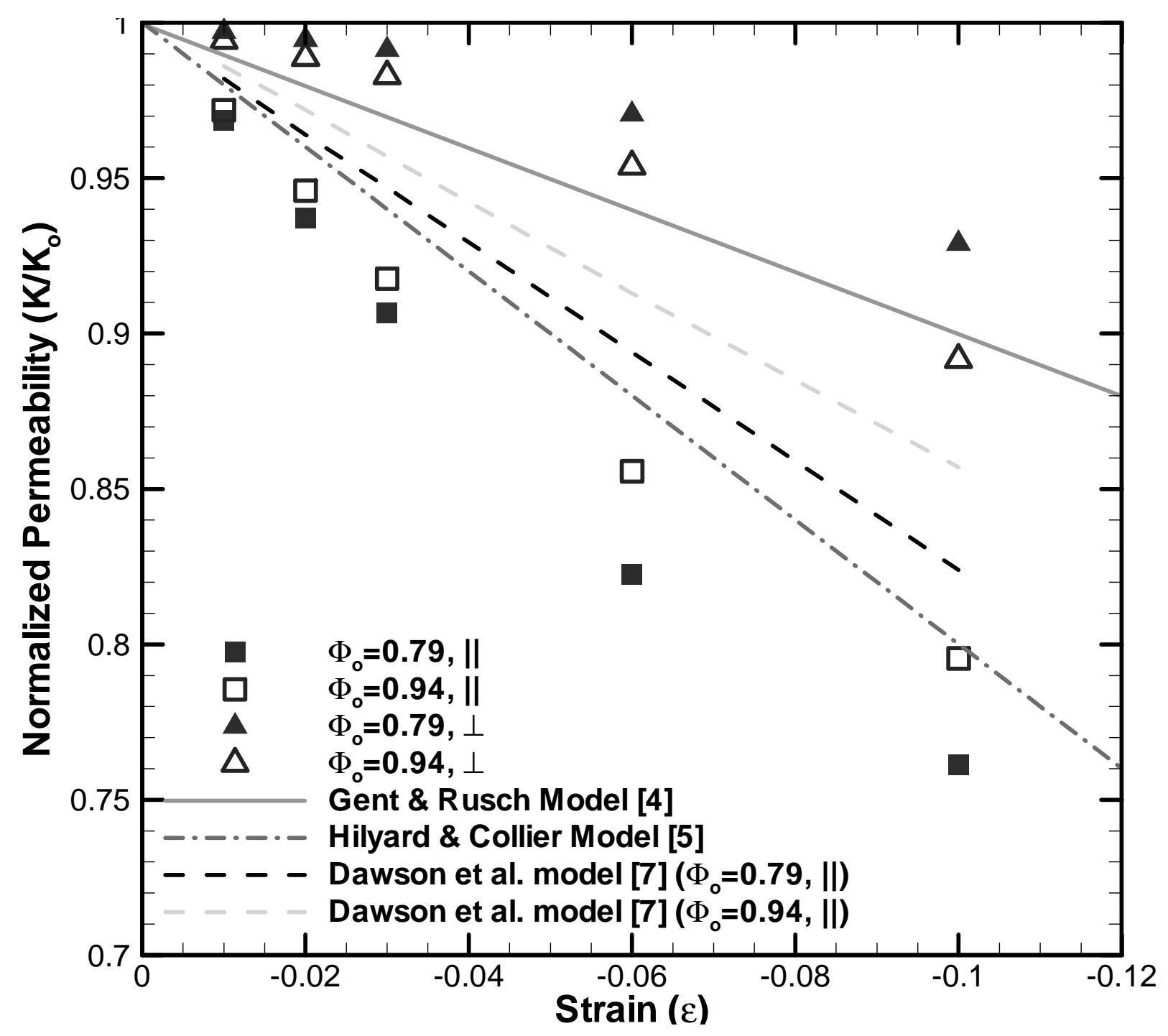

Figure 10. Normalized permeability versus strain for aluminum foams. 


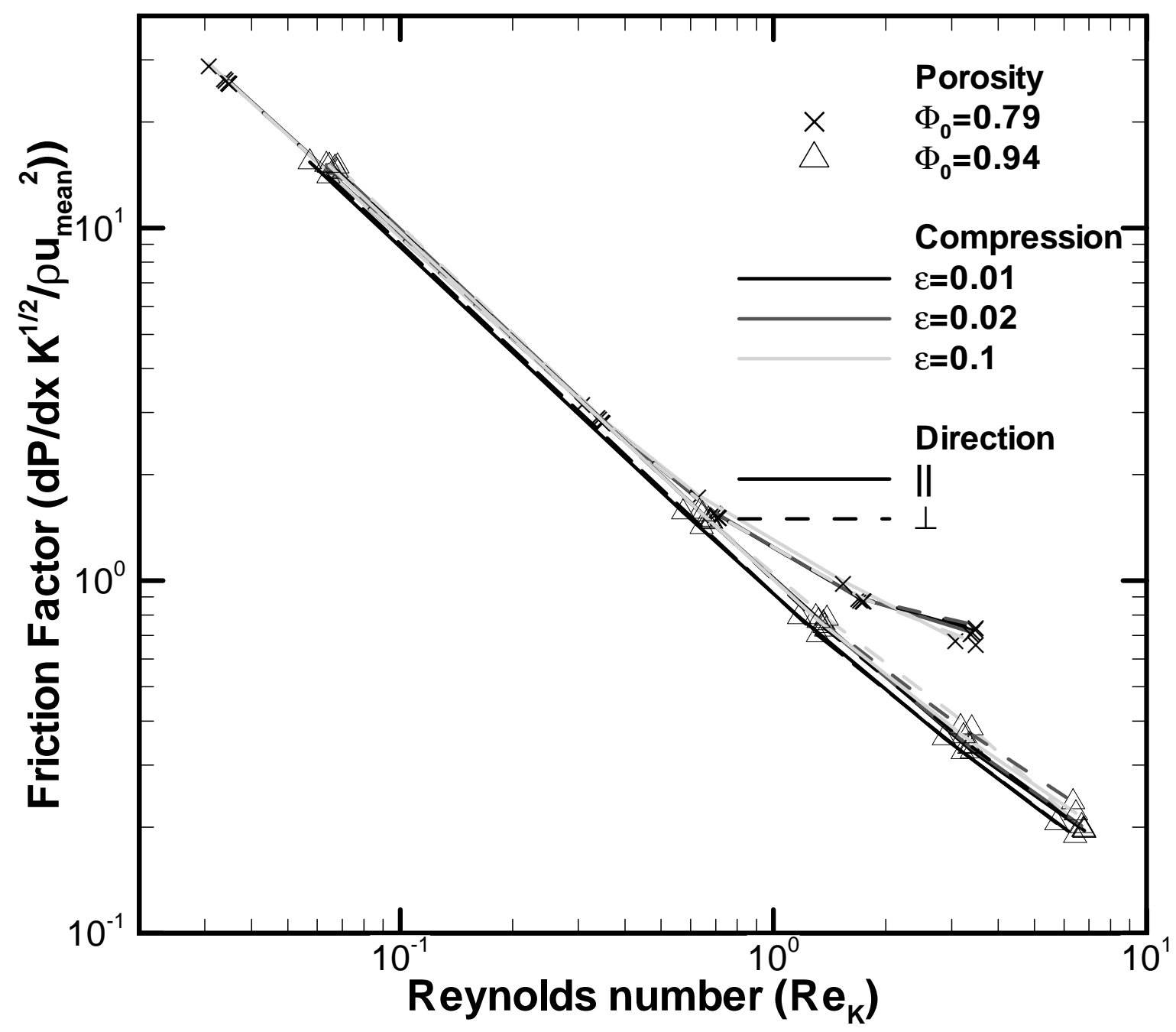

Figure 11. Predicted friction factor versus modified Reynolds number for two base foam porosities $\left(\Phi_{0}\right.$ $=0.79$ and 0.94$)$ and 4 different compressions $(\varepsilon=0.01,0.02,0.03,0.1)$. 


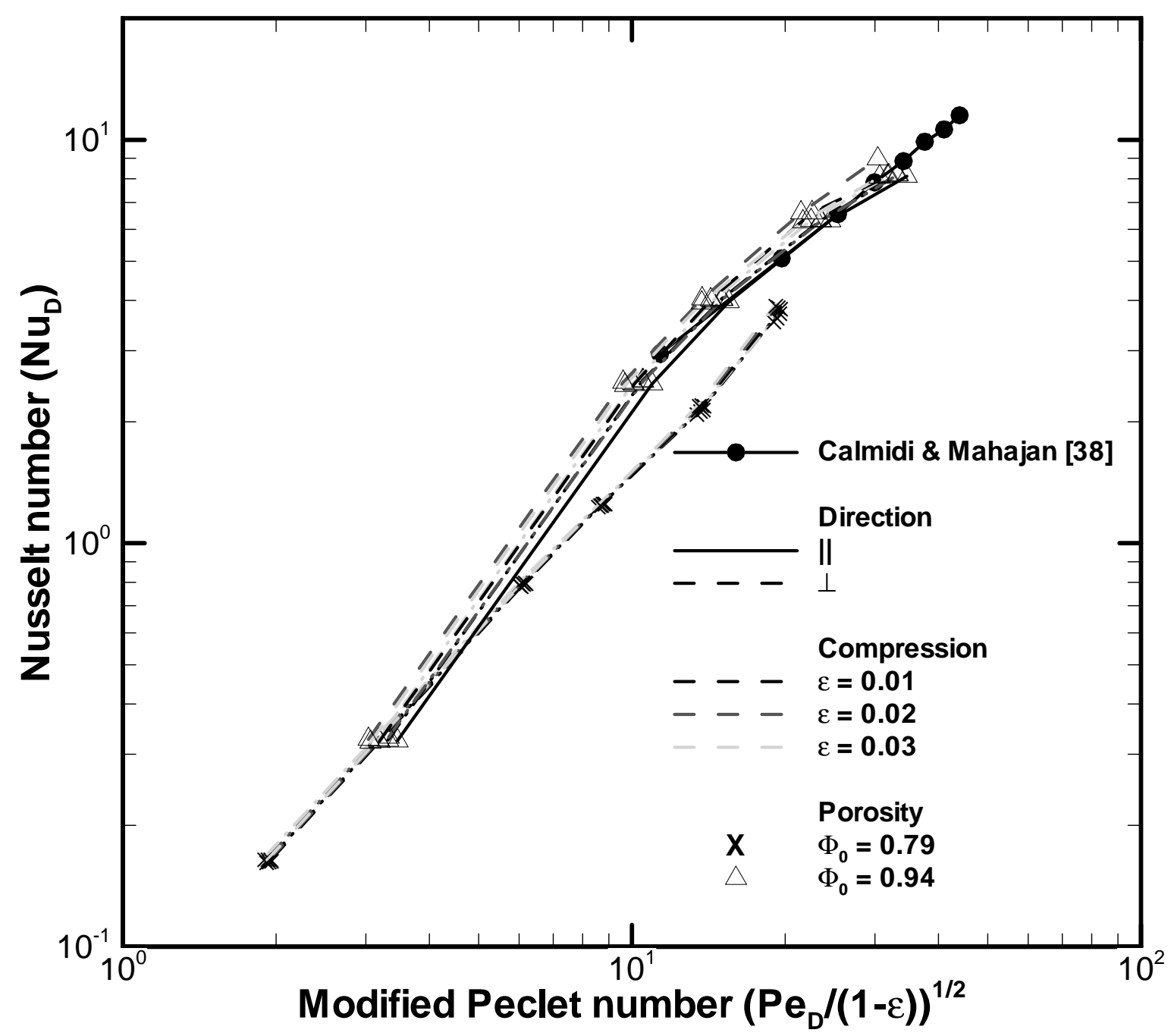

Figure 12. Nusselt number $\left(\mathrm{Nu}_{\mathrm{D}}\right)$ variation with modified Peclet number $\left(\mathrm{Pe}_{\mathrm{D}}\right)$ for two base foam porosities $\left(\Phi_{0}=0.79\right.$ and 0.94$)$ at different compressions $(\varepsilon=0.01,0.02,0.03,0.1)$. 


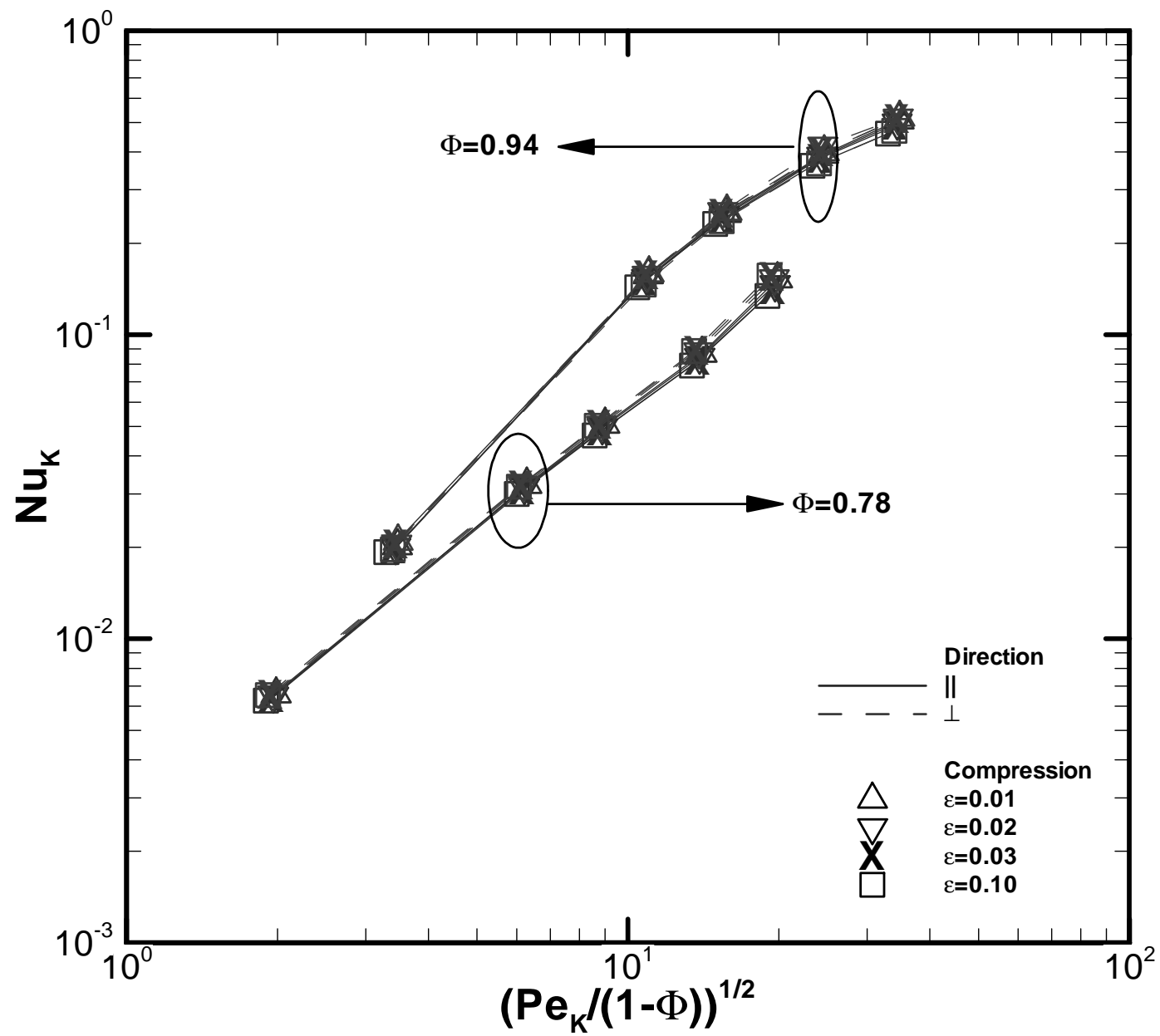

Figure 13. Nusselt number $\left(\mathrm{Nu}_{\mathrm{K}}\right)$ variation with modified Peclet number $\left(\mathrm{Pe}_{\mathrm{K}}\right)$ for two base foam porosities $\left(\Phi_{0}=0.79\right.$ and 0.94$)$ at different compressions $(\varepsilon=0.01,0.02,0.03,0.1)$. 


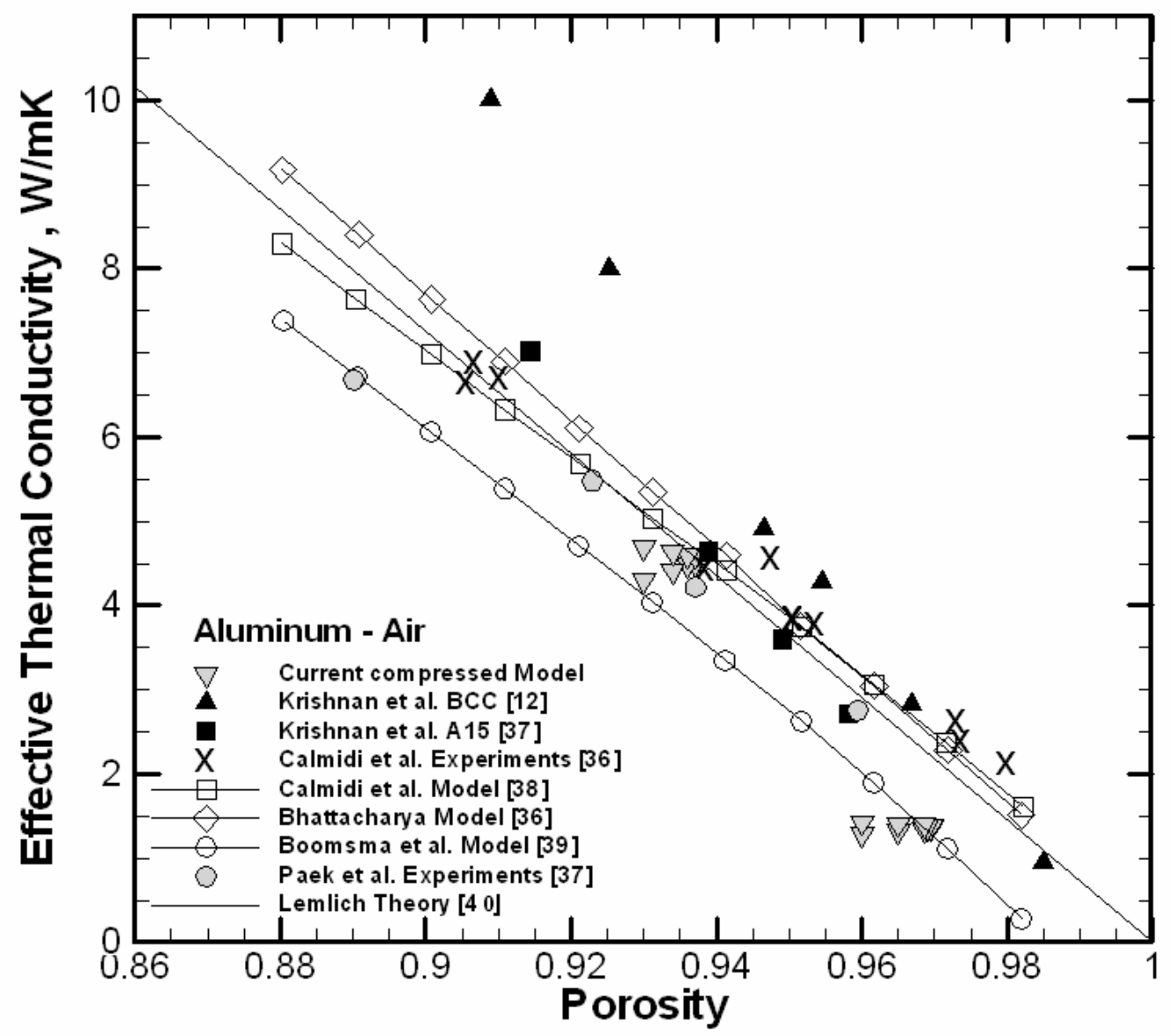

Figure 14. Predicted effective conductivity (k) of compressed aluminum foam-air system for two different porosities. Also plotted are available numerical, semi-empirical models and experimental measurements. 


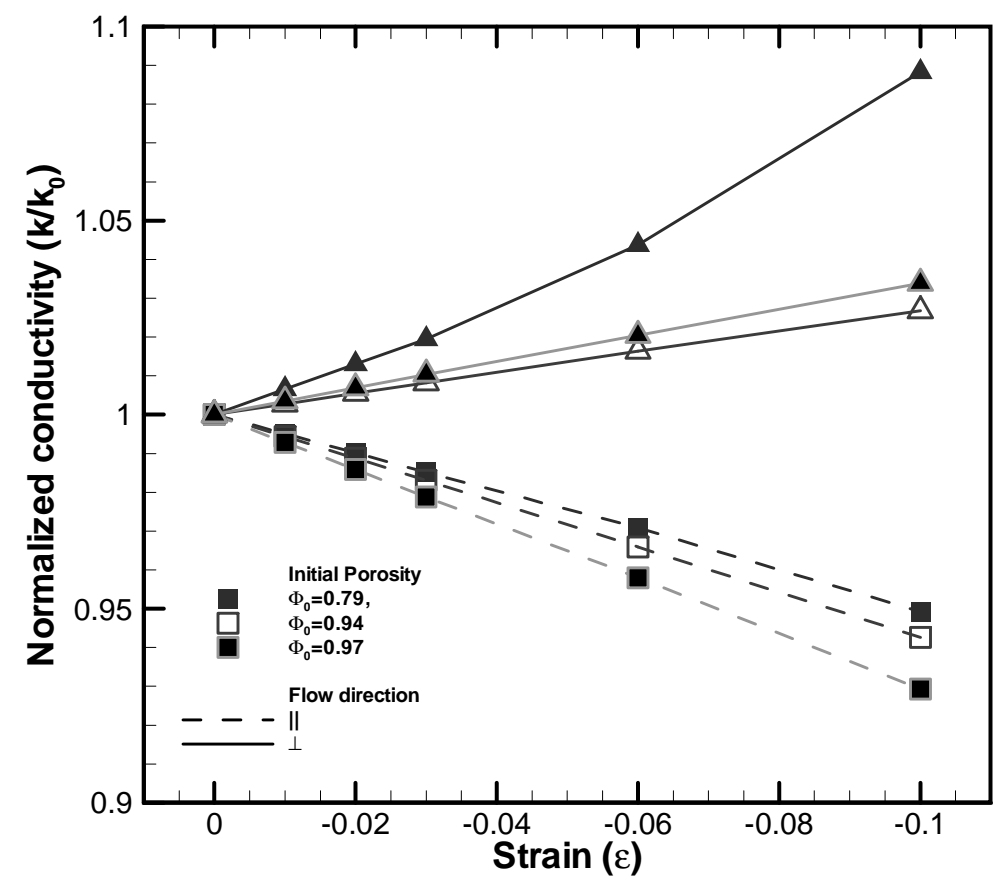

Figure 15. Normalized effective conductivity $\left(\mathrm{k} / \mathrm{k}_{0}\right)$ for the aluminum foam-air system as a function of foam compression. 


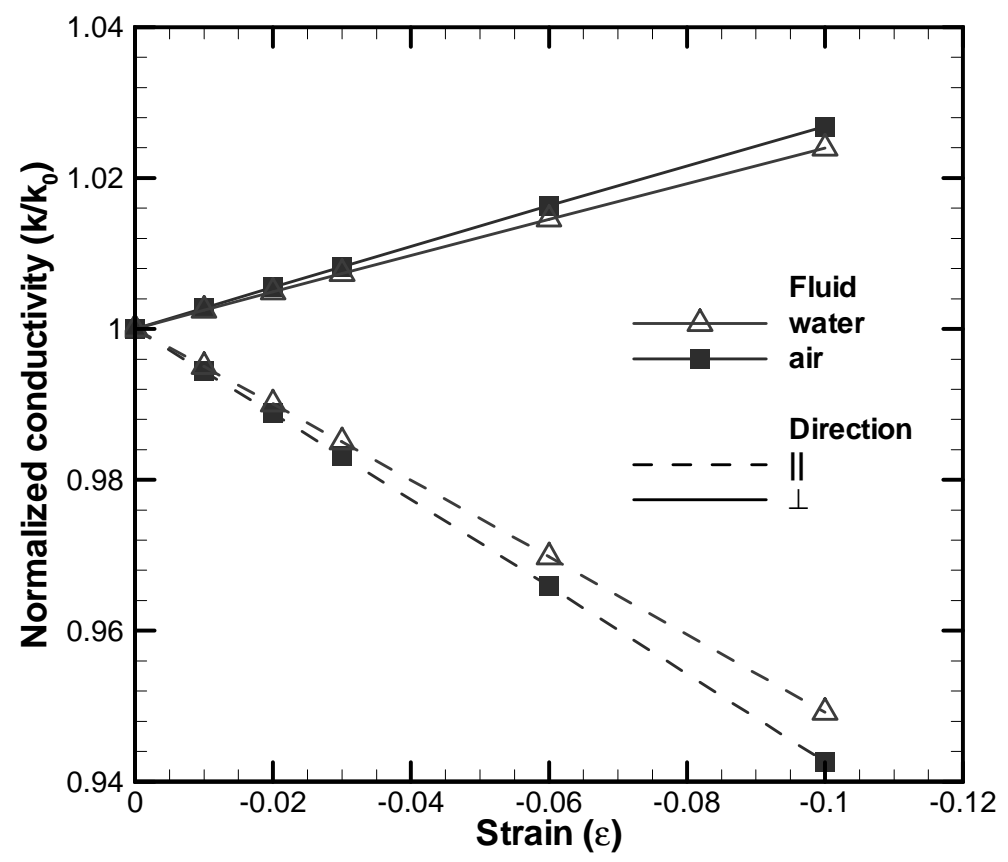

Figure 16. Normalized effective conductivity $\left(\mathrm{k} / \mathrm{k}_{0}\right)$ of aluminum foam-air and aluminum foam-water systems as a function of compression. 


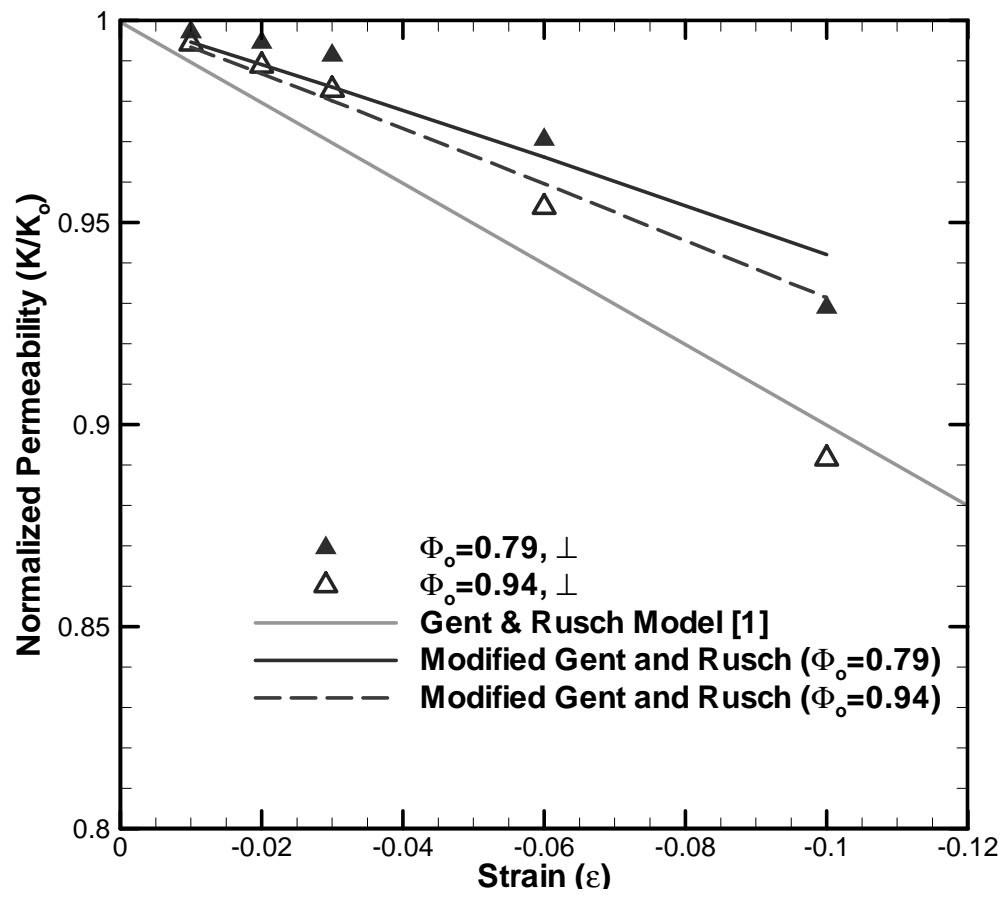

Figure 17. Normalized permeability versus strain in the transverse flow direction. 